Jurnal Adat dan Budaya, Vol.2, No.2 Tahun 2020

ISSN: E-ISSN 2615-6156, P-ISSN: 2615-6113

Jurnal Homepage: https://ejournal.undiksha.ac.id/index.php/JABI/index

\title{
ANALISIS DAN PERANCANGAN ASSET GAME RUMAH DAN PAKAIAN ADAT BALI BERBASIS PIXEL ART 2D
}

\author{
Jasson Prestiliano ${ }^{1}$, Debora Puspita Sarisih ${ }^{2}$, Birmanti Setia Utami ${ }^{3}$ \\ ${ }^{123}$ Program Studi Desain Komunikasi Visual, Universitas Kristen Satya Wacana \\ E-mail: jasson.prestiliano@uksw.edu
}

\begin{abstract}
Abstrak
Bali merupakan salah satu pulau di Indonesia yang memiliki khasanah budaya yang sangat luas dan kaya. Kebudayaan Bali memiliki filosofi yang mendalam, khususnya dalam pakaian adat dan rumah adatnya. Namun belum banyak pelaku seni modern, khususnya perancang seni game yang mengetahui makna dan filosofi setiap bentuk dan warna tersebut. Hal ini membuat mereka merancang sejauh yang mereka lihat saja. Penelitian ini membahas tentang perancangan asset game berbasis pixel art $2 D$ dengan ciri khas Bali. Tujuan penelitian ini adalah membuat asset pixel art $2 D$ dengan menggunakan ciri khas Jawa. Penelitian ini menggunakan metode kualitatif dan strategi linear. Didapatkan hasil bahwa Pakaian dan Rumah adat Jawa memiliki ciri khas yang berbeda-beda serta memiliki berbagai filosofi yang berbeda dalam setiap bentuknya, sehingga hasil perancangan ini dapat menjadi panduan desain pixel art $2 D$ bagi para pengembang game dan perancang seni game agar tidak menghilangkan filosofinya. Manfaat untuk para pemain game hasil perancangan ini dapat memberikan ilmu budaya tentang pakaian adat dan rumah adat Bali.
\end{abstract}

Kata Kunci: Kebudayaan Bali; Pakaian Adat Bali; Rumah Adat Bali; Aset game, pixel art 2D

\begin{abstract}
Bali is one of the islands in Indonesia that has a rich and wide culture. Balinese culture has deep philosophy, especially in its traditional clothes and traditional houses. However, not many modern artist, especially game artist that know know the meaning and the philosophy of each form and color. This reason made them design the art related to Bali only as far as they see. This study discusses the design of 2D pixel art based game assets with Balinese characteristics. This study uses qualitative methods and linear strategies. The result is that the clothes and traditional houses of Bali have different characteristics and have different philosophies in each form, so the results of this design can be a 2D pixel art design guide for game developers and game artist so they will not to eliminate the philosophy. The advantage for the game players will give them the cultural knowledge about Balinese traditional clothes and traditional houses.
\end{abstract}

Keywords: Balinese culture; Balinese Traditional Clothes; Balinese Traditional House; Game Asset; Pixel Art 2D

\section{PENDAHULUAN}

Pulau Bali memiliki banyak kebudayaan yang menarik dan unik, serta menjadi salah satu ikon Indonesia yang menjadi daya tarik bagi wisatawan (Suwardani, 2015). Keunikan budaya ini juga menarik perhatian banyak pengembang konten multimedia yang sekarang ini sedang berkembang pesat sebagai media pendidikan dan pengetahuan. Salah satu jenis dari konten multimedia tersebut adalah game, yang memiliki sisi interaktivitas dalam medianya. Pengembang game banyak yang tertarik untuk mengabadikan budaya Bali tersebut dalam bentuk karakter game atau objek lain di dalam gamenya.

Berdasarkan beberapa game yang sudah ada banyak game yang menggunakan ciri khas budaya Pulau Jawa dan Bali, karena Pulau Jawa memiliki banyak kebudayaan dan banyak peninggalan sejarah seperti rumah adat, pakaian adat yang memiliki filosofi khas dan nilai sejarah, serta kebudayaan dan keunikan yang hanya dimiliki oleh Pulau Jawa dan Bali (Wayan, 2019).

Sayangnya belum banyak ditemukan kajian yang cukup mendalam mengenai rumah dan pakaian adat Bali dalam pengembangan karakter di dalam berbagai game, sehingga kebanyakan 
game hanya melihat dari internet tentang bentuknya kemudian melakukan perancangan ulang tanpa memikirkan filosofinya. Hal ini membuat beberapa perancangan menjadi kehilangan nilai filosofis dan budaya, hanya bentuknya saja yang mirip, sehingga tidak dapat mengedukasi masyarakat pemain game mengenai budaya Bali yang sebenarnya.

Beberapa penelitian sebenarnya telah memulai untuk mengerjakan kajian mendalam mengenai penggunaan budaya Indonesia di dalam sebuah game. Penelitian yang berjudul "Penerapan unsur Budaya Indonesia Pada Aplikasi Game Tetris Nusantara Berbasis Android" penelitian ini menjelaskan tujuan manfaat game, dan mengenalkan keanekaragaman budaya Indonesia melalui game agar para pemain mendapatkan pengetahuan budaya Indonesia melalui game tetris (Agung, 2014). Sedangkan pada penelitian yang berjudul "Representasi tokoh pewayangan purwa pandawa gagrag Surakarta" penelitian ini bertujuan untuk merancang representasi tokoh pewayangan purwa pandawa gagrak Surakarta sebagai acuan desain tanpa meninggalkan makna dan identitas karakternya (Maharani, 2019).

Pixel art untuk game dapat terlihat indah walaupun sederhana. Selain itu, pixel art memiliki ukuran file yang kecil karena memanfaatkan setiap bagian atau detail pixel dalam satu sprite dan melalui perhitungan komputasi dalam penyimpanannya (Glauber, 2018). Selain itu pixel art juga dapat menjadi karakteristik game yang semakin digemari masyarakat, sehingga diciptakan oleh developer game sekarang ini dengan gaya pixel art ini menjadi pengalaman yang ditawarkan oleh game developer modern kepada para pemain game. Pixel Art 2D masih banyak diminati oleh para pemain game, terutama pada game buatan developer Indonesia yang berbasis Mobile dan game indie yang dirilis di Steam (Podgorski,2015).

Karena itu, pada penelitian kali ini akan ditelaah, dianalisis dan dirancang asset game berbasis pixel art 2 Dimensi untuk karakter dan objek rumah yang memenuhi kaidah yang benar sesuai dengan bentuk, warna dan filosofis dari rumah dan pakaian adat Bali. Tujuannya adalah selain untuk mengedukasi masyarakat pemain game tentang rumah dan pakaian adat Bali, juga memberikan standar pemahaman bagi para perancang game dan game artist agar membuat karakter yang tidak kehilangan nilai-nilai filosofis budaya Bali saat memutuskan akan menggunakan Budaya Bali di dalam game yang dikembangkannya. Penelitian ini juga dapat dipergunakan sebagai acuan untuk karya-karya artistik lainnya yang berbasis komputer seperti animasi ataupun web comic.

\section{METODE}

Penelitian ini menggunakan metode kualitattif dan strategi linear, dilakukan pengumpulan data melalui observasi, review dokumen dan wawancara (Sarwono, 2006). Tahapan penelitian dapat dilihat pada gambar 1.

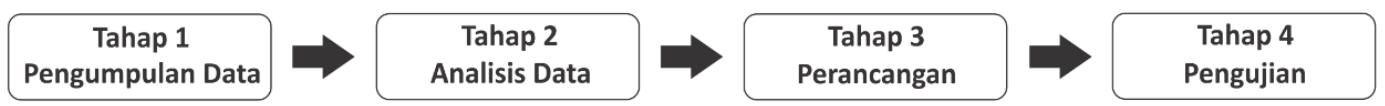

\section{Gambar 1. Tahap Penelitian}

[Sumber: Dokumentasi Sarwono, 2006]

Pada tahap pengumpulan data, dilakukan pengumpulan data secara kualiatif dengan mewawancarai bapak I Wayan Lovayana $27^{\text {th }}$, mengenai filosofi yang terkandung dalam setiap bentuk rumah adat dan pakaian adat Bali. Tahap analisis data dilakukan berdasarkan data-data hasil wawancara yang telah dikumpulkan pada tahap sebelumnya menyimpulkan makna yang terkandung agar sesuai terhadap masalah yang ada, sehingga tujuan perancangan asset game berbasis pixel art 2D dapat disampaikan dengan baik. Pada tahap perancangan yang dilakukan yaitu 
perancangan asset pixel art 2D, tahapan yang dilalui dalam proses perancangan ini dapat dilihat pada Gambar 2.

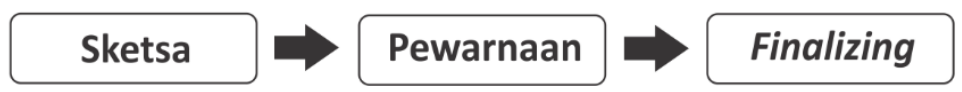

Gambar 2. Proses Perancangan

[Sumber: Dokumentasi Sarwono, 2006]

Tahap pengujian dilakukan dengan cara mewawancarai bapak I Wayan Lovayana sebagai salah satu pakar budaya Bali mengenai hasil gambar pixel art 2D apakah sudah sesuai dengan bentuk dan filosofinya.

\section{HASIL DAN PEMBAHASAN}

\subsection{Analisis dari Hasil Pengumpulan Data}

Hasil pengumpulan data dianalisis kemudian dirancang konsep dengan tepat sesuai kebutuhan. Rumah adat Bali dalam satu lingkungannya terbagi menjadi beberapa bentuk bangunan yang dilihat dari jumlah tiangnya, meliputi sakepat (empat tiang), sakenem (enam tiang), dan sakutusi/sakewulu (delapan tiang) dari masing-masing ruangan ini memiliki fungsi dan kegunaan masing-masing, tidak hanya ruangan saja tetapi terdapat pemerajaan yaitu pura keluarga. Dari beberapa bentuk bangunan terdiri dari beberapa elemen, yaitu undag (tangga) dan bebaturan (kaki), sesaka (badan), dinding, serta usus/iga-iga (kepala) dan Raab (kepala), dari beberapa elemen ini masing-masing memiliki filosofis. Dan pakaian adat Bali untuk laki-laki terdiri dari kain kamen, kampuh/saput, umpal (selendang kecil), baju, udeng (ikat kepala). Sedangkan pakaian adat untuk perempuan menggunakan kamen, senteng (selendang), ikat kepala dan pepusungan. Hasil dari bentuk-bentuk beserta filosofinya ini lah yang akan dibuat dalam perancangan asset game berbasis pixel art $2 D$.

\subsection{Perancangan Asset 2D Pixel Art}

Pakaian adat Bali laki-laki berupa kamen dengan lipatan untuk laki-laki kamen/wastra melingkar dari kiri kekanan (melawan arah jarum jam) mempunyai makna sebagai pemegang dharma, tinggi kamen laki-laki kira-kira sejengkal dari telapak kaki yang mempunyai makna sebagai penanggung jawab dharma harus melangkah dengan panjang tetapi harus tetap melihat tempat yang dipijak adalah dharma. Menggunakan kampuh (saput) penggunaannya sama seperti kamen yang melingkar berlawanan arah jarum jam (prasawya) dan tinggi saputan kira-kira satu jengkal dari ujung kamen atau selutu, mempunyai makna untuk menutupi kejantanan atau simbolisasi dari nafsu saja. Menggunakan kancut (lelancingan) sebagai simbol kejantanan, dengan ujung yang lancip dan sebaiknya menyentuh tanah (menyapu jagat), ujung kancut yang kebawah mempunyai makna sebagai simbol penghormatan terhadap ibu pertiwi. Menggunakan selendang kecil (umpal) yang mempunyai makna kita sudah mengendalikan hal-hal yang buruk, ikatan umpal berada disebelah kanan yang mempunyai makna dharma memegang kendali, pada saat laki-laki memakai baju umpal harus terlihat sedikit agar kita pada saat kondisi apapun siap memegang teguh dharma.

Kemudian dilanjut dengan menggunakan baju/penutup badan (kwaca) dengan syarat bersih, rapi dan sopan. Baju merupakan penutup dada dan perut yang mempunyai makna simbolisasi menutup ego dan kesombongan pada diri manusia. Pada saat pergi ke pura harus menunjukan rasa syukur kita yang diwujudkan dengan memperindah diri. Menggunakan ikat kepala (udeng/destar) 
simbol dari memusatkan pikiran (ngiket manah) yang merupakan sumber penggerak panca indra, karena itu udeng harus diikat dengan kedua ujung simpul atau muncuk udeng harus lurus kea rah atas, memiliki simbol sang pemakai memantapkan untuk berfikir lurus menuju yang diatas, kedua ujung udeng merupakan simbolisasi menjunjung konsep "rwabhineda" merupakan akar dari keyakinan pada karma phala, dan sekarang bergeser dengan berbagai variasi miring ke kiri atau miring ke kanan. PHDI Bali (Parisadha Hindu Darma Indonesia) menetapkan udeng untuk ke pura harus berwarna putih yang mempunyai makna kesan kejernihan pikiran dan kedamaian pikiran, undung berkabung undeng berwarna hitam dan untuk kegiatan social lainnya berwarna batik atau warna lain selain hitam dan putih.

Udeng jejateran (udeng untuk persembayangan) menggunakan simpul hidup didepan diselasela mata sebagai lambang cundamani atau mata ketiga dan sebagai lambang pemusatan pikiran, dengan ujung menghadap ke atas sebagai simbol penghormatan pada sang Hyang Aji Akasa. Udeng ini memiliki dua bebidakan yakni sebelah kanan lebih tinggi dan sebelah kiri lebih rendah yang mempunyai simbol bahwa kita harus mengutamakan dharma, bebidakan yang kiri simbol Dewa Brahma dan catur purusa artha, yang kanan simbol Dewa Siwa dan simpul hidup melambangkan Dewa Wisnu. Pada bagian atas kepala dan rambut masih terlihat tidak tertutupi yang mempunyai makna masih meminta (brahmacara). Dan juga sebagai simbolisasi catur purusa artha, dimana bidak kanan lebih tinggi mempunyai makna dalam hidup, materi (artha) merupakan tujuan yang diutamakan untuk mejalankan kehidupan ini, bidak kiri lebih rendah, merupakan simbol keinginan (kama) yang hanya bisa dicapai apabila artha sudah dicapai dan lis lipatan udeng dengan simpul udeng (ngiket) didepan merupakan simbol Dharma, dimana setiap kegiatan dalam pencapaian Artha dan Kama harus berdasarkan dharma/agama. Gambar sketsa pakaian adat madya Bali dapat dilihat pada gambar 3, hasil perwarnaan pakaian adat madya Bali dapat dilihat pada gambar 4, dan finalizing pakaian adat madya Bali dapat dilihat pada Gambar 5. Sedangkan gambar sketsa pakaian adat agung Bali dapat dilihat pada Gambar 6, hasil perwarnaan pakaian adat Agung Bali dapat dilihat pada Gambar 7, dan finalizing pakaian adat agung Bali dapat dilihat pada gambar 8.
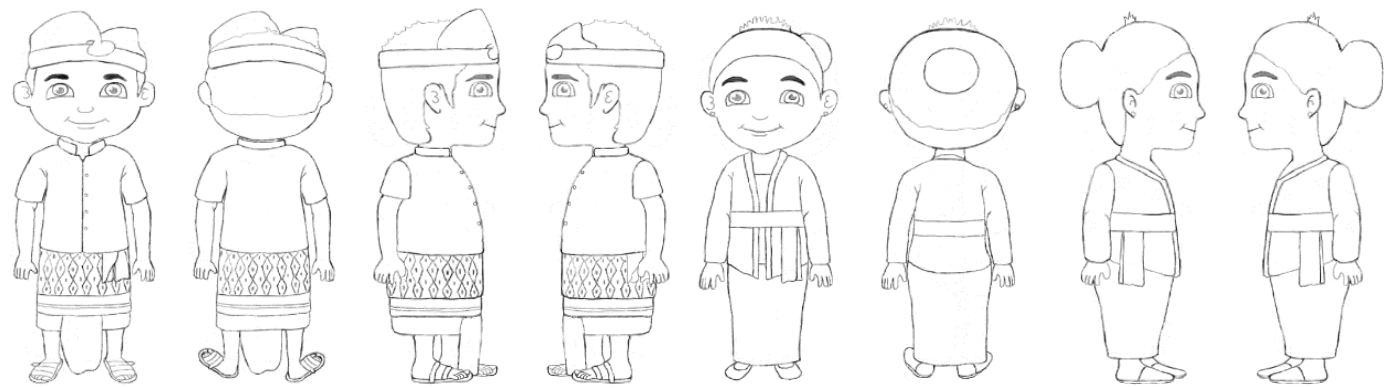

Gambar 3. Sketsa Pakaian Adat Madya Bali

[Sumber: Dokumentasi Debora Puspita Sarisih, 2020] 


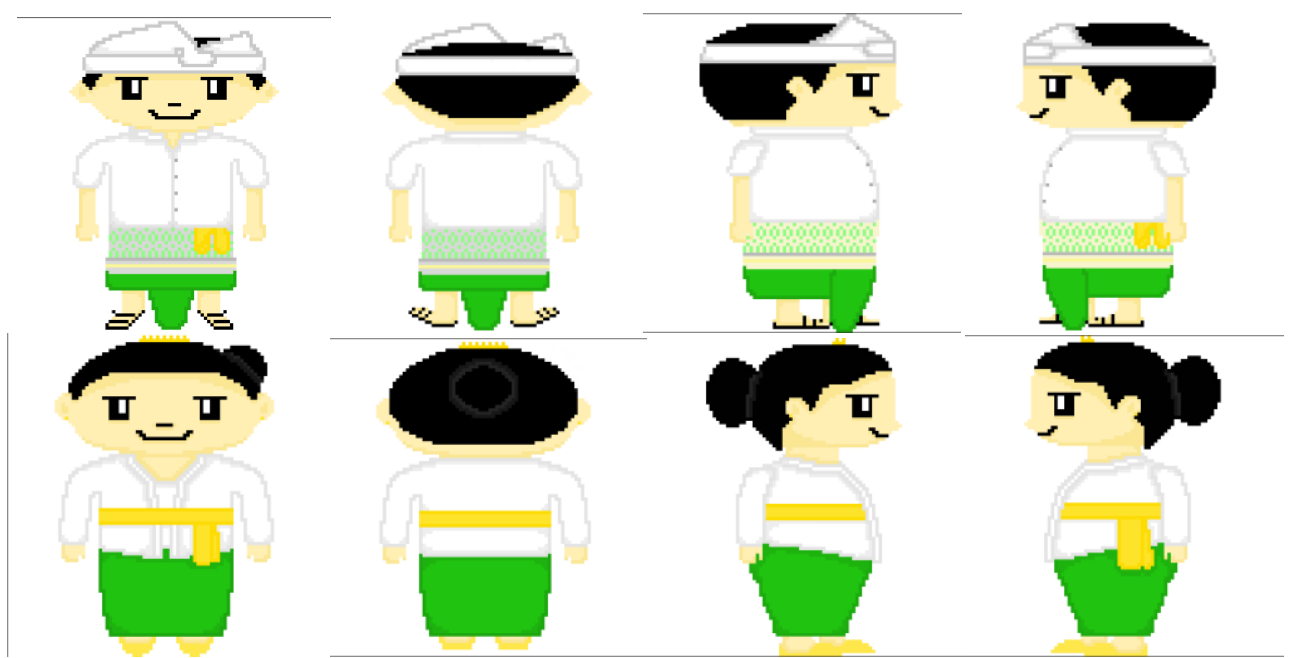

Gambar 4. Pewarnaan Pakaian Adat Madya Bali

[Sumber: Dokumentasi Debora Puspita Sarisih, 2020]

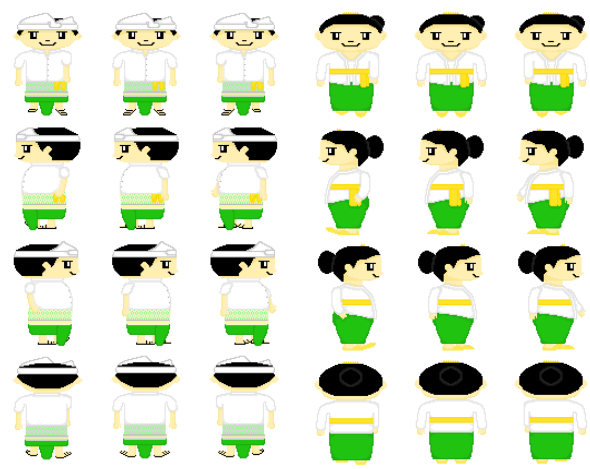

Gambar 5. Finalizing pakaian adat madya Bali

[Sumber: Dokumentasi Debora Puspita Sarisih, 2020]
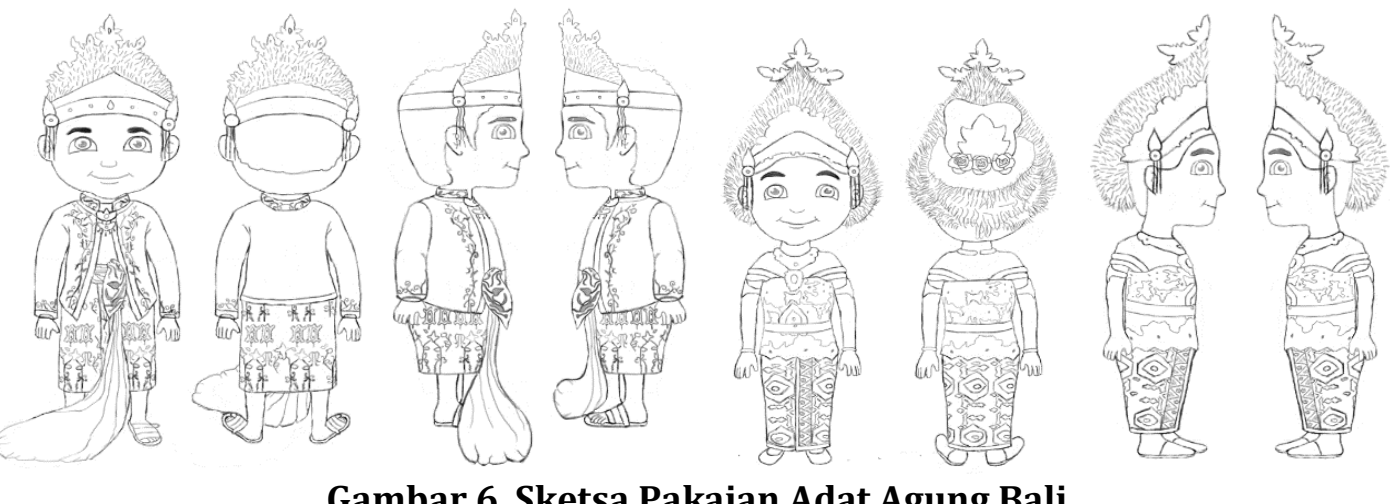

Gambar 6. Sketsa Pakaian Adat Agung Bali

[Sumber: Dokumentasi Debora Puspita Sarisih, 2020] 

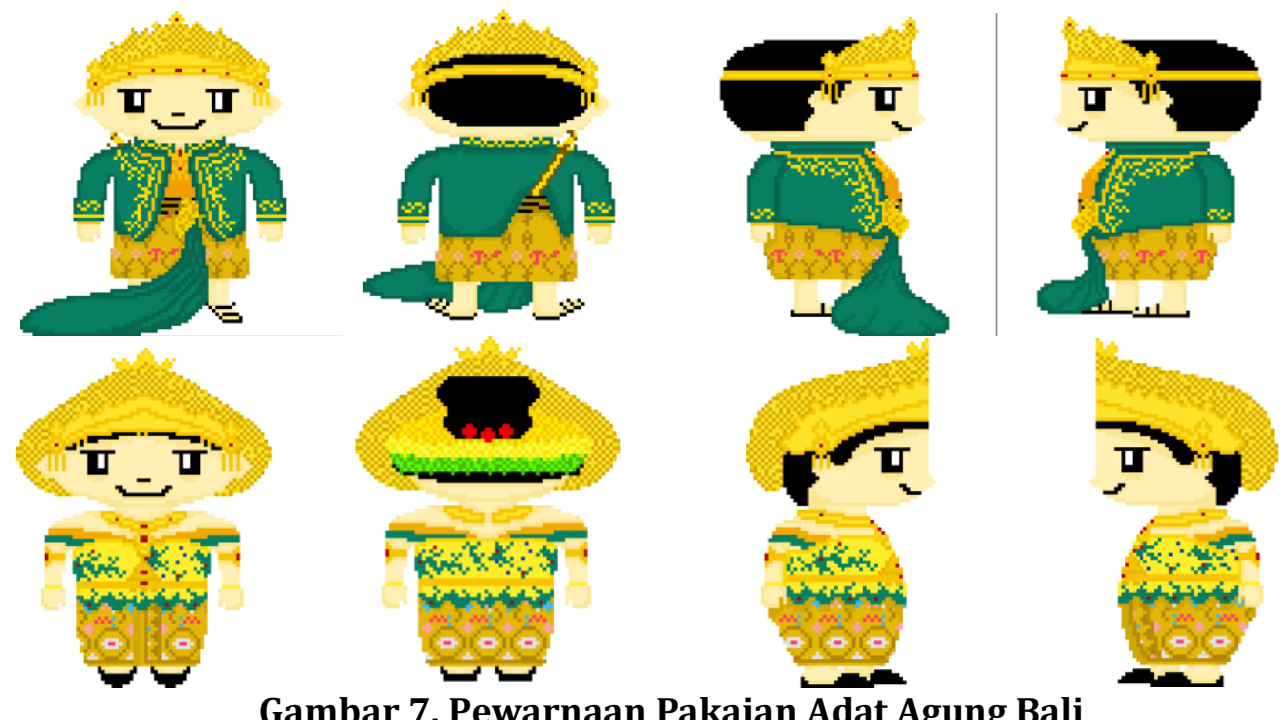

Gambar 7. Pewarnaan Pakaian Adat Agung Bali

[Sumber: Dokumentasi Debora Puspita Sarisih, 2020]

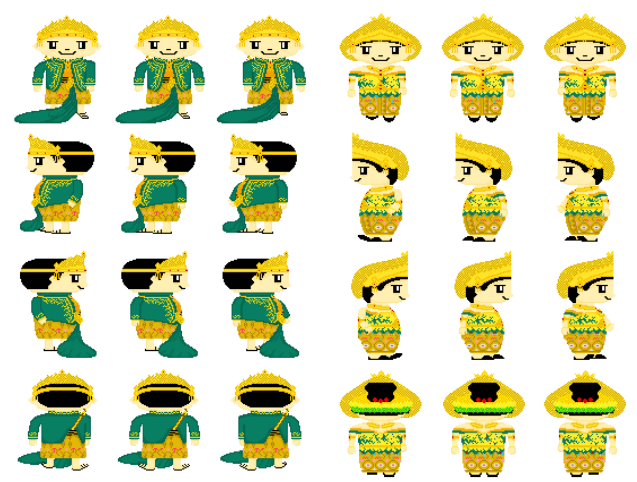

Gambar 8. Finalizing Pakaian Adat Agung Bali

[Sumber: Dokumentasi Debora Puspita Sarisih, 2020]

Rumah adat Bali memiliki standart satuan ukur tersendiri yang disebut dengan gegulak, yang diambil berdasarkan ukuran fisik pemilik bangunan, dan diaplikasikan dengan menggunakan sebilah bambo sebagai modul dasar. Menurut konsep tri angga yang mengelompokan bentuk rumah menjadi 3 bagian yaitu, kepala, badan dan kaki. Bentuk bangunan yang dimakzud, diantaranya bebaturan (kaki bangunan) dan undag (tangga), yaitu bentuk rumah yang sangat mempengaruhi proporsi dan skala pada bangunan rumah Bali, mempunyai sifat terbuka dan mempunyai makna untuk memisahkan level antara bangunan dengan taman, hewan, atau hal lain yang bersifat kotor dan bebas berkeliaran.

Bentuk Sesaka (badan/tiang), berbentuk seperti tiang-tiang yang memiliki fungsi sebagai penguat. Usuk/iga-iga (kepala), bahan bangunan atap rumah adat Bali menggunakan bahan-bahan dari alam, seperti rotan untuk dinding, sirap bambu dan alang-alang untuk struktur dan atap bangunan. Tentu hal ini berkaitan dengan essensi arsitektur Bali yang menjunjung tinggi hubungan dengan alam. Rumah adat Bali terbagi menjadi beberapa ruangan berdasarkan jumlah tiang dalam satu lingkungan, yaitu sakepat (empat tiang) yang berfungsi sebagai tempat tidur dan dapur. Gambar pembuatan background rumah adat Bali ruang sakepat dapat dilihat pada gambar 9 dan tileset rumah adat Jawa Bali ruang sakepat dapat dilihat pada gambar 10. 

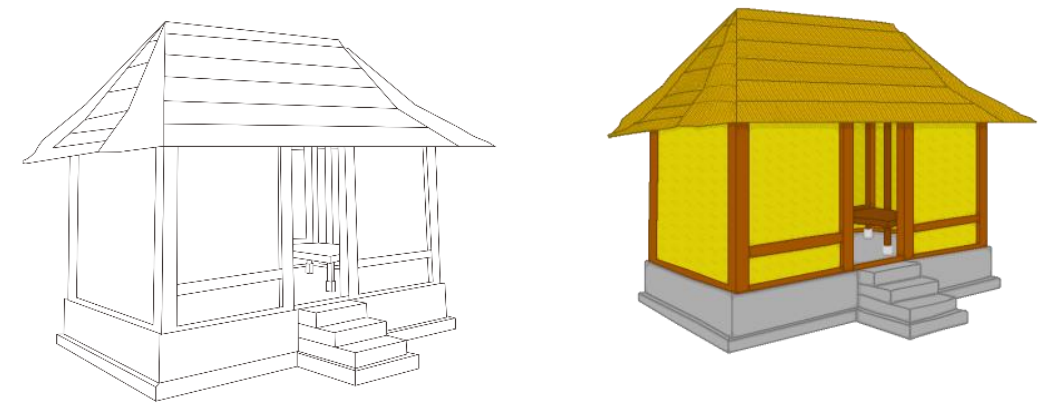

Gambar 9. Pembuatan Background Rumah Adat Bali Ruang Sakepat

[Sumber: Dokumentasi Debora Puspita Sarisih, 2020]

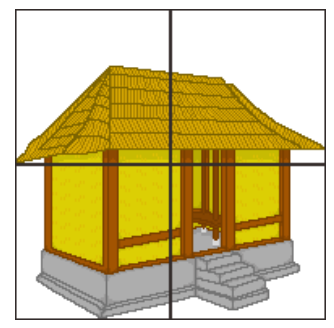

Gambar 10. Tileset Rumah Adat Bali Ruang Sakepat

[Sumber: Dokumentasi Debora Puspita Sarisih, 2020]

Sakenem (enam tiang), berfungsi sebagai tempat lumbung padi. Dibuat dengan pilotis (diangkat dari tanah) agak tinggi, agar bahan makanan terlindung dari hewan dan banjir. Pada bagian atas terdapat pintu lubang untuk tempang peralatan senjata, seperti keris. Gambar pembuatan background rumah adat Bali ruang sakenem dapat dilihat pada Gambar 11 dan tileset rumah adat Jawa Bali ruang sakepat dapat dilihat pada Gambar 12.
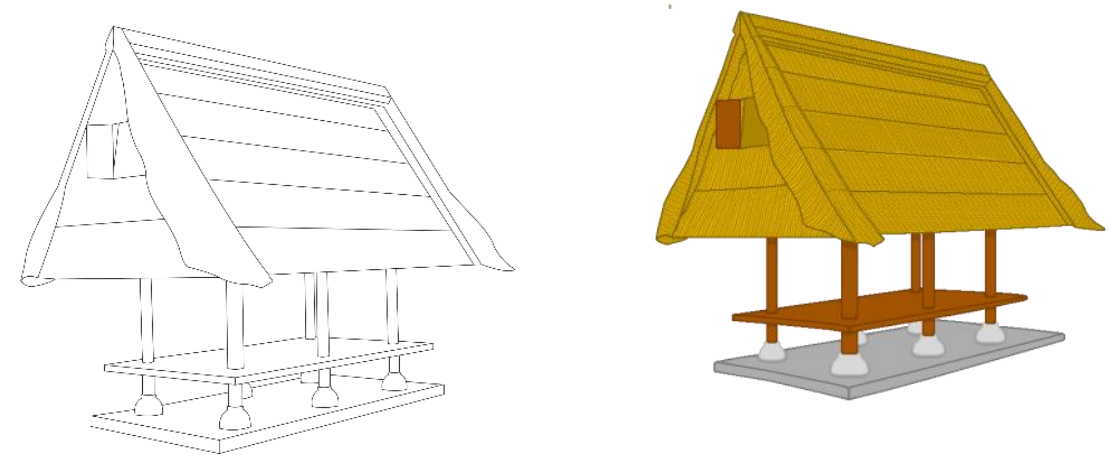

Gambar 11. Pembuatan Background Rumah Adat Bali Ruang Sakenem [Sumber: Dokumentasi Debora Puspita Sarisih, 2020]

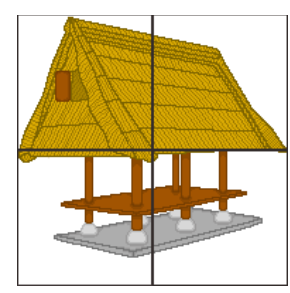




\section{Gambar 12. Tileset Rumah Adat Bali Ruang Sakenem}

[Sumber: Dokumentasi Debora Puspita Sarisih, 2020]

Sakewulu/ sakutusi (delapan tiang), berfungsi sebagai ruang publik atau balai agung. Gambar pembuatan background rumah adat Bali ruang sakewulu dapat dilihat pada Gambar 13 dan tileset rumah adat Jawa Bali ruang sakewulu dapat dilihat pada gambar 14.
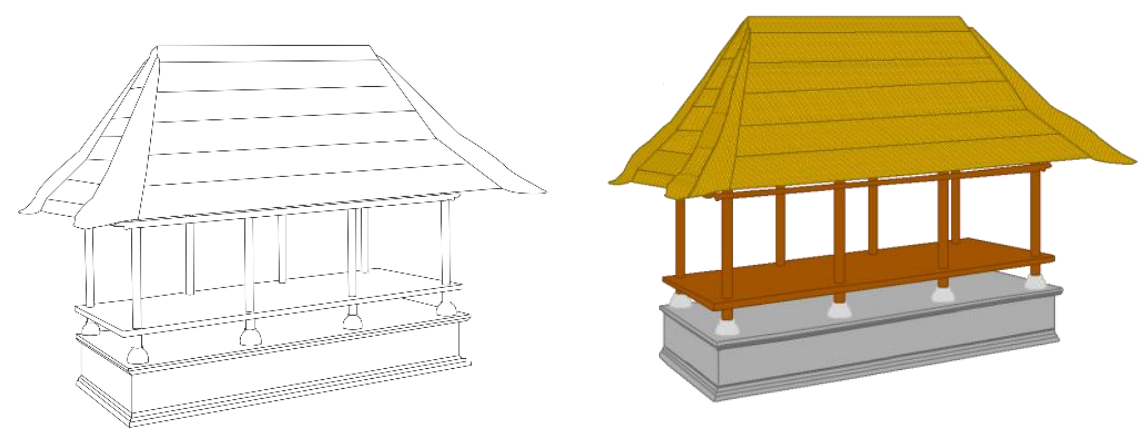

Gambar 13. Pembuatan Background Rumah Adat Bali Ruang Sakewulu [Sumber: Dokumentasi Debora Puspita Sarisih, 2020]

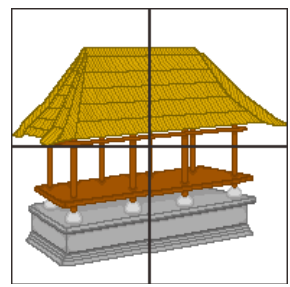

Gambar 14. Tileset Rumah Adat Bali Ruang Sakewulu

[Sumber: Dokumentasi Debora Puspita Sarisih, 2020]

Pura keluarga (pemerajaan), berfungsi sebagai tempat beribadah keluarga atau pemujaan. Bentuk bangunan yang paling menonjol, yaitu bagian atap yang bertumpuk disebut dengan atap meru, menggunakan bahan material ijuk. Pemerajaan ini mempunyai empat sisi dinding dengan pintu dibagian depan. Gambar pembuatan background rumah adat Bali pura keluarga dapat dilihat pada gambar 15 dan tileset rumah adat Jawa Bali pura keluarga dapat dilihat pada gambar 16.
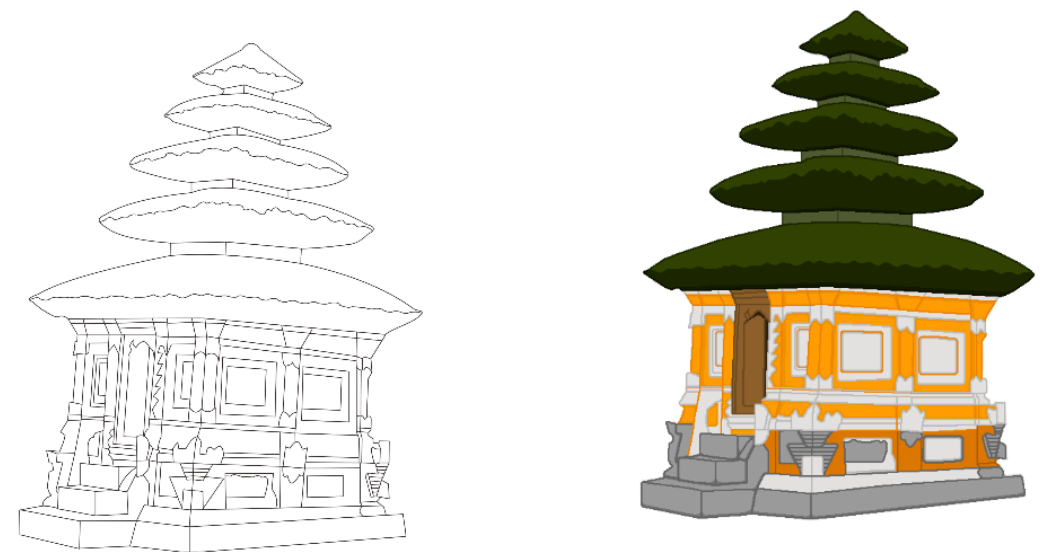

Gambar 15. Pembuatan Background Rumah Adat Bali Pura Keluarga

[Sumber: Dokumentasi Debora Puspita Sarisih, 2020] 


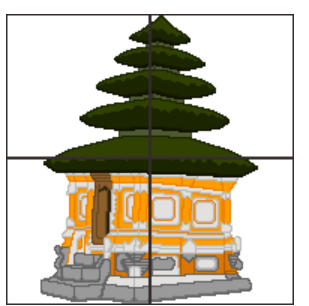

Gambar 16. Tileset Rumah Adat Bali Pura Keluarga

[Sumber: Dokumentasi Debora Puspita Sarisih, 2020]

\subsection{Pengujian}

Hasil review untuk pakaian adat dan rumah adat Bali yang dilakukan oleh bapak I Wayan Lovayana, bahwa hasil pixel art $2 D$ untuk pakaian adat dan rumah adat sudah sesuai, tetapi untuk pakaian adat agung laki-laki terdapat revisi penambahan bentuk keris. Gambar review pakaian adat agung Bali dapat dilihat pada gambar 17.

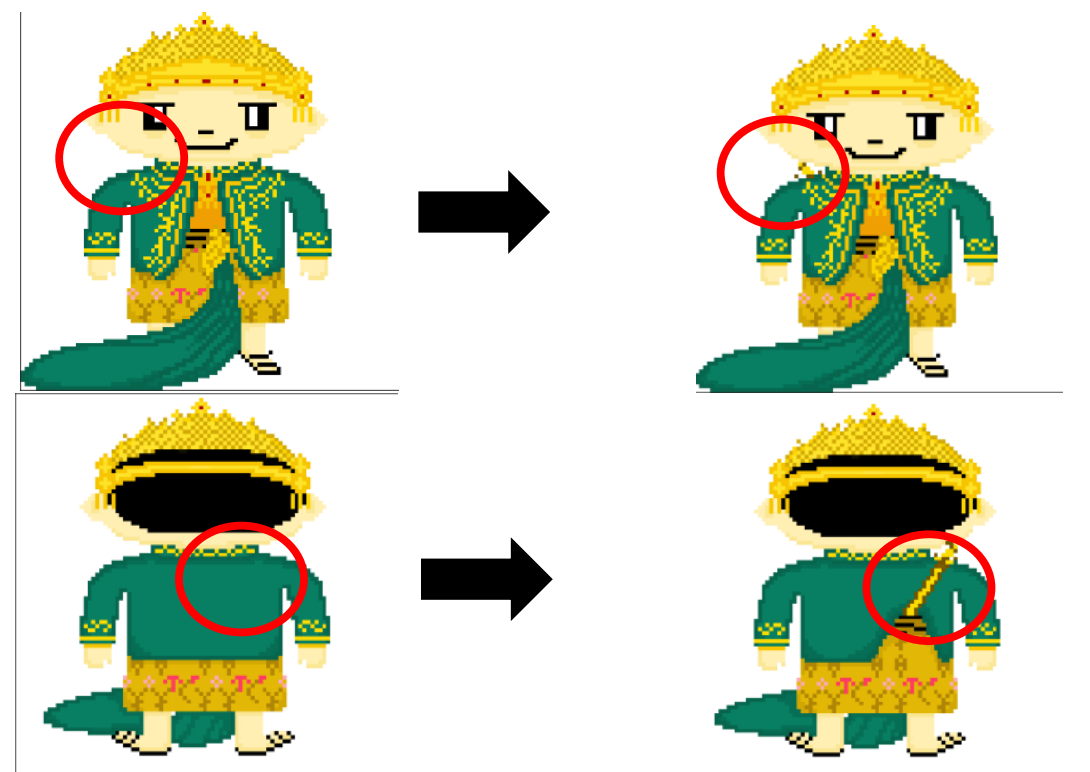

\section{Gambar 17. Review Pakaian Adat Jawa Tengah Gaya Yogyakarta}

[Sumber: Dokumentasi Debora Puspita Sarisih, 2020]

Selain hal yang diperbaiki tersebut, desain dan ornament yang ada baik pada karakter pixel art dengan pakaian adat Bali maupun pada rumah adat Bali telah sesuai dengan filosofis yang ada.

\section{KESIMPULAN}

Indonesia memiliki banyak kekayaan budaya, khususnya keanekaragaman budaya di Bali. Pakaian adat dan rumah adat Bali yang memiliki ciri khas dan filosofi didalam setiap bentuknya sangat menarik untuk diteliti lebih lanjut.

Pakaian adat dan rumah adat Bali yang diimplementasikan ke dalam bentuk asset game pixel art $2 D$ ini dapat menjadi panduan desain pixel art $2 D$ untuk para pengembang game dan para perancang game. Panduan dan acuan untuk karakter versi pixel art ini setelah diuji, dapat dianggap tidak menghilangkan makna filosofi yang terkandung didalamnya. Hal ini dikarenakan setiap bentuk dari pakaian adat dan rumah adat didalamnya memiliki filosofi yang saling berkaitan satu sama lain 
Selain untuk para perancang game, karakter pixel art dengan pakaian adat bali dan rumah adat bali ini dapat dipergunakan untuk karya lain yang menggunakan basis pixel art dalam pembuatannya, seperti animasi maupun komik.

\section{DAFTAR PUSTAKA}

Agung, Albertus. 2014. Penerapan unsur budaya Indonesia pada aplikasi game tetris nusantara berbasis android.

Arrafiani. 2012. Rumah etnik Bali. Jakarta: Griya Kreasi.

Ame, Taiyo. 2016. Panduan menggambar manga chibi dengan pensil. Jakarta: Transmedia Pustaka.

Glauber. 2018. Indroduction to pixel art for games. (Updated 18 Juli 2012 ) URL: Introduction to Pixel Art for Games [Diakses pada 4 Juni 2019]

Maharani, Penina Inten, Utami, Birmanti Setia \& Prestiliano, Jasson. 2019. Representasi tokoh pewayangan purwa pandawa gagrag Surakarta. Gondang: Jurnal seni dan budaya.

Podgorski, Daniel. 2012. Style by necessity:FTL:Faster than light, and pixel art as a new cubism. (Updated 30 September 2015) URL: dari https://thegemsbok.com/art-reviews-andarticles/video-game-reviews-mid-week-mission-ftl-faster-than-light-subset-games/ [Diakses pada 11 Juni 2019]

Suwardani, Ni Putu. 2015. Pewarisan nilai-nilai kearifan local untuk memproteksi masyarakat bali dari dampak negative globalisasi. Jurnal kajian Bali.

Sarwono, Jonathan. 2006. In J. Sarwono, metode penelitian kuantitatif dan kualitatif. Yogyakarta: Graha Ilmu.

Wayan. 2019. 10 hal unikyang hanya ada di Bali. (Updated 13 Maret 2020) URL: https://www.watersport-bali.com/10-hal-unik-yang-hanya-ada-di-bali/ [Diakses Pada 16 Maret 2020] 